\title{
Anti-Theft System for Car Security using RFID
}

\author{
Eze, P. C. ${ }^{\# 1}$, Achebe, P.N. ${ }^{* 2}$, Jeremiah, L. ${ }^{\# 3}$, Ageh, T. A. ${ }^{* 4}$ \\ ${ }^{\# 1,3}$ Department of Electrical and Electronic Technology, Covenant Polytechnic, Owerrinta, Abia, Nigeria \\ ${ }^{* 2}$ Department of Electrical and Electronic Engineering, Chukwuemeka Odumegwu Ojukwu University, Uli \\ ${ }^{* 4}$ Technology Incubation Centre, Nnewi, Anambra, Nigeria
}

\begin{abstract}
The use of Radio Frequency Identification (RFID) system for security purposes is becoming increasingly common because of the cost effectiveness of the technology. This paper has presented an anti-theft system for car security using RFID. The system combines Arduino Uno module and RFID technologies. Initial design was carried out using Proteus software for implementing the Arduino electronic circuit. Serial communication link exists between the RFID and the Arduino. An immobilizer that ensured that the car engine stops if other strategies fail was incorporated as security strategy. The system was built considering cost effectiveness and operational efficiency.
\end{abstract}

Keywords - Arduino Uno, Immobilizer, RFID, Security,

\section{INTRODUCTION}

Increasing crime rate requires sophisticated technological tactics or solution to effectively curb its menace. This has been effectively applied in such area like security access control, where biometric technology has been largely deployed to checkmate falsification of user identities. Also, alarm system that enable intruders to be detected and the closed circuit television (CCTV) that capture incidence of crime are now readily available. Fashioning technology to provide robust security of human life and property will no doubt curb or reduce to near zero.

One of such areas where such security system has been largely used to secure property is the car theft alarm system. Car hijacking or theft is becoming increasingly common these days. Increasing car theft has spurred the creation of anti-theft systems [1]. In order to address the issue of car theft, a superb security should be given to a car. For example, the report by Singh et al [2], stated that security of vehicle from various types of cases of burglary can be provided by vehicle focal locking framework -a security gadget Nevertheless, it does not seem to guarantee complete security and openness to the vehicle when burglary occur Singh et al [2] . Vehicle Tracking System (VTS) using Global Positioning System (GPS) and Global System for Mobile (GSM) communication innovation has been implemented.

Securing human material possession from loss or theft has become necessary due to the economic implication. For instance, a report by Tech Crunch [3,4] stated that citizens of the United States on average, lost one smart phone yearly, which resulted to 30 billion dollar loss of money in 2012. This highlight the need to develop a system that will afford car owners to be conscious of possible case of intruder. Several types of alarm systems that use various technology have recently been developed and implemented in literature. These technologies include but not limited to GPS systems, Wireless sensor, 2D Barcodes, Radio Frequency Identification (RFID) tags, GSM technology, combine GSM and GPS technology etc. However, such system should have considerable ease of use, owner's convenience, reliability and cost effectiveness.

This paper aims to develop a car anti-theft security system. The objective is to provide advance security system that supports users to lock and secure their cars and things within it. To achieve the aim of this paper, the present system uses the Arduino Uno and RFID technologies integrated together to develop a cost effective security system for car owner(s).

The remaining part of this paper is divided into literature review, material and method, result, and conclusion.

\section{LITERATURE REVIEW}

The term anti-theft system is a technology that is used for protecting and deterring theft action [5, 6]. Earlier, conventional setting up of security personnel's to guard target locations has been the practice. However, this has gradually be replaced by different technologies that ensure sophisticated security in target places and even remote location. Some of these technologies are concisely reviewed in this section, and are RFID system, barcode system, biometric system, smartcard and so on. Generally, the security systems can be referred to as automatic identification systems. This technology tracks the identity of an object and automatically exchange the information of the object with no physical connection [6-8]. Figure 1 presents an overview of automatic 
identification (Auto-ID) technology. The Automatic identification system is capable of improving the flow of information and tracking system. As it can be seen in Fig. 1, Automatic identification system is applicable in such technologies as RFID and others.

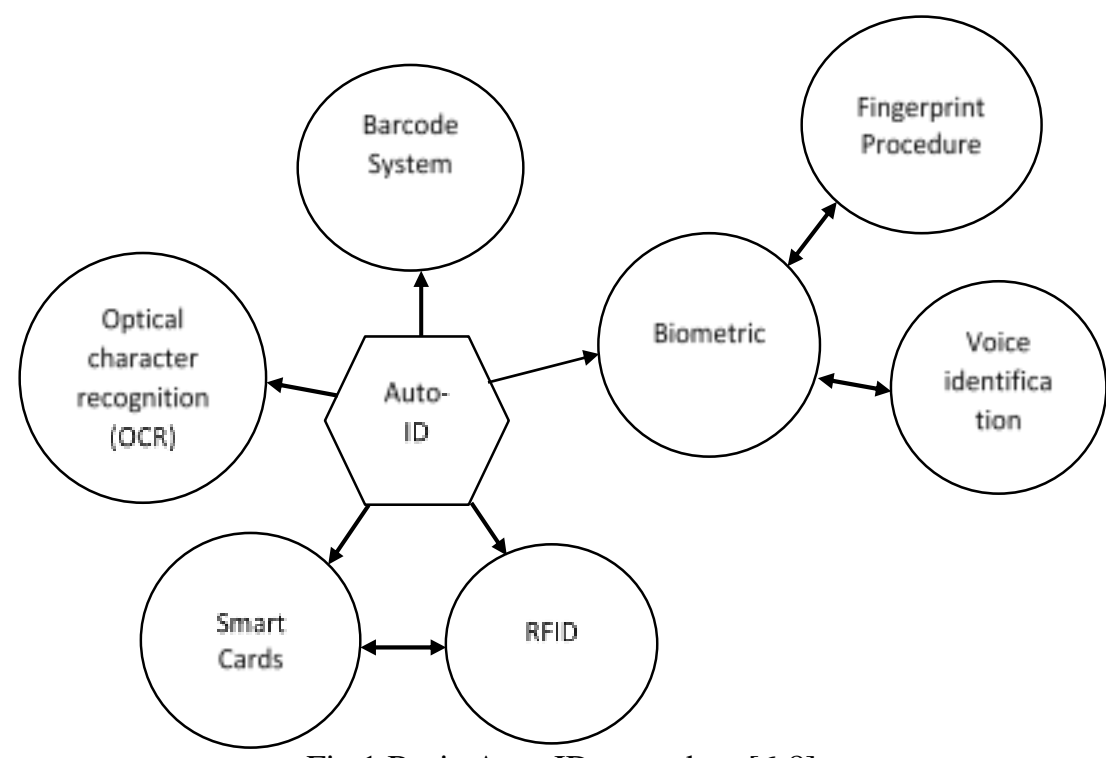

Fig.1 Basic Auto-ID procedure [6-8]

\section{A. Closed Circuit Television ( CCTV) System}

The CCTV camera has been deployed extensively in places like department stores, small groceries, shopping malls, school communities, within cities and towns, financial institutions and so on. This technology has greatly improved security and surveillance work in busy places and even remote locations. However, installing CCTV is quite cost demanding and as such organizations are gradually shifting attention to more affordable technology in terms of cost effectiveness.

\section{B. Barcode System}

Barcode comprises vertical black bars isolated by white gaps that are arranged in parallel form [6-8]. Figure 2 shows a barcode. There are wide and thin magnitude that are organized based on a predetermined code to designate a corresponding number and symbol [6]. Barcode information are read and decoded using a laser from an optical scanner. Though they appear identical in physical design, each barcode stands for distinctive code in the list of item.

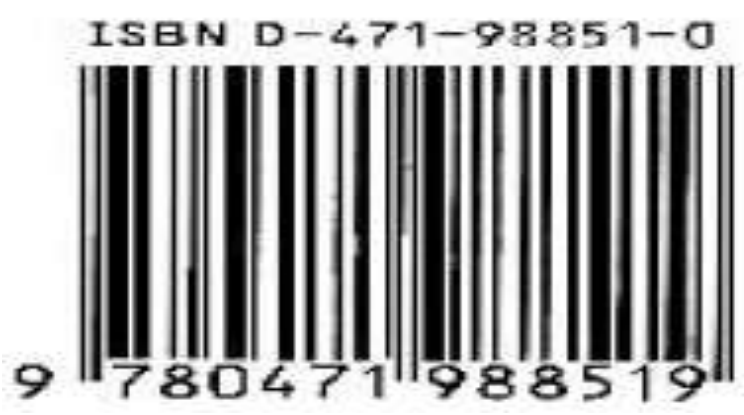

Fig. 2 A typical barcode [5,6,9]

\section{Optical Character Recognition}

It is an application that automatically scan characters using optical device. The most essential merit of optical character recognition (OCR) systems is the fact that it allows the conversion and storage of scanned document in pdf or image fie from camera into editable or text document [7]. The area where OCR has been widely deployed include educational sector, government (public) institution, and banking institution. For instance, in the banking sector, OCR is used to process checks in order to avoid human oversight and support paper work digitalization. Nevertheless, certain drawbacks or limitations are found using OCR as a result of the 
relative high cost of quality device and the poor quality of document scanned, which usually give out noise and distorted characters [6].

\section{Biometric System}

The conventional methods of identification in terms of identity (ID) cards, personal identification number (PIN), or password, has proven not to be reliable for secured security purposes. An alternative and viable technology that uses exclusive physiological and behavioural traits for identification or verification has been widely used for secured security purposes. This technology is known as biometric system. These unique traits are: fingerprints, faces, irises, retinal patterns, hand geometry, hand writing, signature, palm printing, and voice $[10,11]$. Some biometric systems can use only single trait in such case they are called unimodal biometric system. Others can combine more than one trait in such case they called multimodal biometric systems. Typically, a biometric system consist of the following subsystems: sensing, feature, extraction, template matching and output [12]. Its operation is basically of two phases, which are: enrolment and recognition [13-15] as shown in Fig. 3.

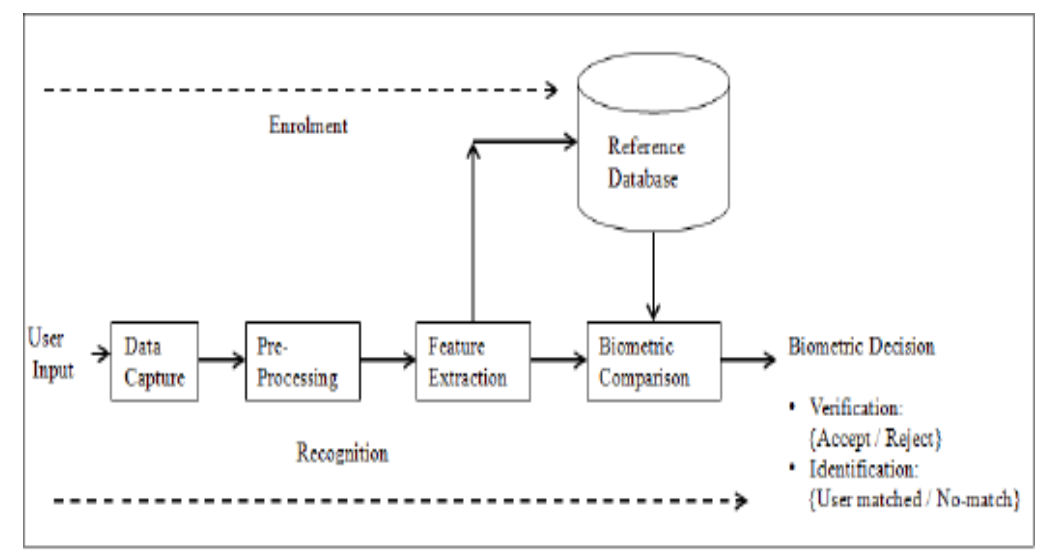

Fig. 3 Componets of a biometric system [15].

\section{E. Smart Card}

Smart card is data storage system that has microprocessor that provides additional computing capacity which is embedded into a plastic enclosure [7]. It has programmable memory for recording user defined data. Smart cards can be categorized in terms of their memory and integrated microprocessor. Data protection from theft is achieved by encryption mechanism. Also, update of data can be achieve when new application is made available to the public even after purchased by user. They are widely used in financial sector for making less expensive and secured financial transaction. Nevertheless, maintaining this technology is expensive, and also, it is vulnerable to wear, corrosion, and dirt [6].

\section{F. Radio Frequency Identification System}

Radio Frequency Identification (RFID) system is a technology that automatically perform identification and tracks tag attached to objects using radio waves. That is, information sharing between tags and reader is carried out through wireless link for object or human identification. It requires no line of sight between the tag (transponder) and reader. It consists of two main hardware elements which are the tag and the reader. The tag is placed on the object to be scanned and it consists of a RFID transceiver for data transfer. RFID tags are of two kinds, namely, Active tags and passive tags. The passive tags consists of three elements: in-built chip, substrate, and antenna. Active tags has the same components with a relatively larger size of micro-chip than that of passive tags. It should be noted that in RFID tags performance, the antenna shape provides significant function [16].

The micro-chip tags of RFID systems are designed to operate at certain license free frequencies. These frequencies include high frequency (HF), 13.56 MHz; microwave, 2.45 GHz; ultra-high frequency (UHF), 868$930 \mathrm{MHz}$; low frequency (LF), 125-135 KHz; and microwave, $5.8 \mathrm{GHz}$ [16]. Figure 4 shows the fundamental working principle of a RFID system. The tag is either active or passive. It reacts to the signals from the reader (or writer or integrator) which in turns transmits signals to the computer [16]. 


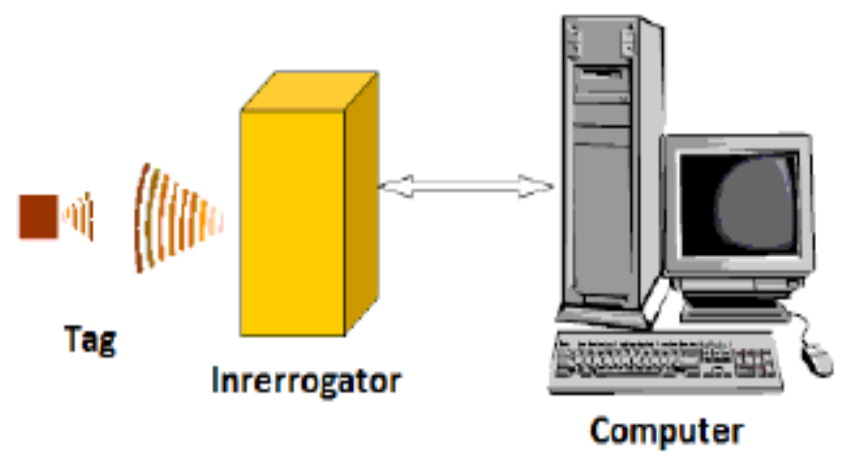

Fig. 4 Fundamental working of RFID [16]

One of the benefits of RFID systems implementation is its utilization as anti-theft and monitoring application [6]. This technology has gain wide acceptability because of the cost effectiveness it offers over CCTV. According to [6], RFID provides viable advantage compare to other Auto-ID system as such they are equipped more memory capacity, requires no line of sight between the tag and reader, and capable of long read range. Though smart card might have same memory as RFID system, it speed of reading is less, expensive and requires physical contact between the card and the reader. Also comparing RFID technology to biometric system, the latter is difficult to be copied, have low speed of reading and expensive to make.

RFID system is similar to magnetic strip or barcode. It is used as a substitute of barcode or a magnetic strip which can be seen at the back of Automated Teller Machine (ATM) card or credit card. Being similar to barcode or magnetic strip, RFID systems have to be scanned to get identifying information [15]. The technology of RFID is deployed in various areas including asset tracking, inventory management, controlling access to confined areas, personnel tracking, supply management, ID badging, as key to unlocking car door, automatic payment deduction while using toll booths, building access systems, payment cards, student ID cards, and wireless sensor and mesh networks [16].

\section{G. Related Works}

Vinston et al [1] designed a vehicle anti-theft system using RFID tag which is implemented inside the engine of a vehicle that is to be protected. A security system for ensuring safety of students belongs in college is developed using barcode and RFID based security system [4]. An immobilizer that uses an active RFID technology is developed for anti-theft auto security system in [17]. Weldemedhin, [6] studied different types of RFID based anti-theft system suitable for implementation in Metropolia Electronics laboratory environment to prevent theft taking. A security system for vehicle to prevent theft action is implemented using GPS and GSM communication is implemented in Singh et al [2] and Lomate et al [18].

\section{MATERIAL AND METHOD}

This section provides the material and the method used for realizing the aim of this paper. Some basic terms are defined.

i. Transmitter: identifies the RFID card identity and conveys (or transmits) data to receiver.

ii. Receiver: data is received from transmitter, alarm is activated or deactivated.

iii. Software: programme that provides the instruction for the operation of the entire hardware used in this paper.

\section{A. Material and Tool}

The materials used in this work include Arduino Uno, RFID module, RFID card, $12 \mathrm{~V}$ battery, buzzer and speaker, light emitting diode (LED), $220 \mathrm{ohm}$ resistor, project board, Jumper wires, perforated board, header connectors, switches, project enclosure, black paper, scotch mounting pad. The tools used include knife, glue gun, soldering iron, wire cutter/stripper, solders. The system design was achieved using materials that are readily available and easily to get from local stores.

\section{B. Method}

The information flow pattern for the anti-theft car security system is presented in the flow diagram shown in Fig. 5. 


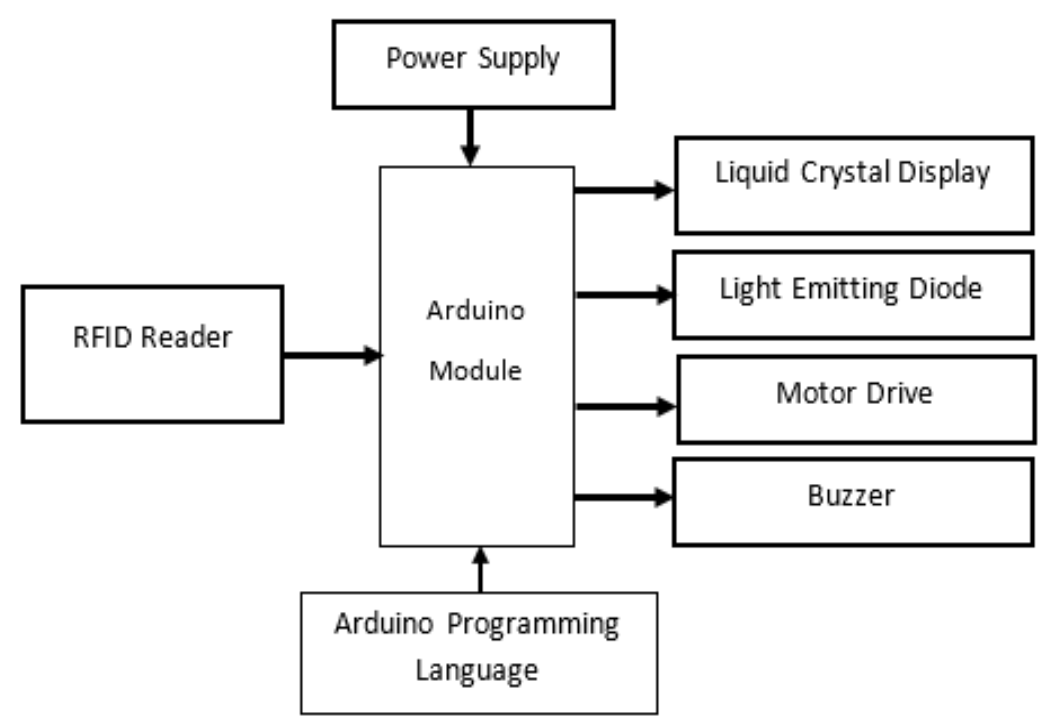

Fig. 5 Flow diagram of anti-theft security for car

The method of design and implementation was initially done using Proteus. The Proteus software was used to design an electronic circuit diagram to establish the link of communication between the RFID module and Arduino Uno. The communication between the RFID module and the Arduino Uno is established serially as shown in Fig.5. Having performed all simulation checks to ascertain the working and operation of the designed circuit, the components were mounted on a project board to carry out physical check so as to ensure that the circuit is working properly before developing a permanent prototype. After performing all necessary tests based on software simulation and temporary circuit implementation, the entire circuitry was mounted on a printed circuit board (PCB). The designed PCB layout circuit diagram is shown in Fig. 7

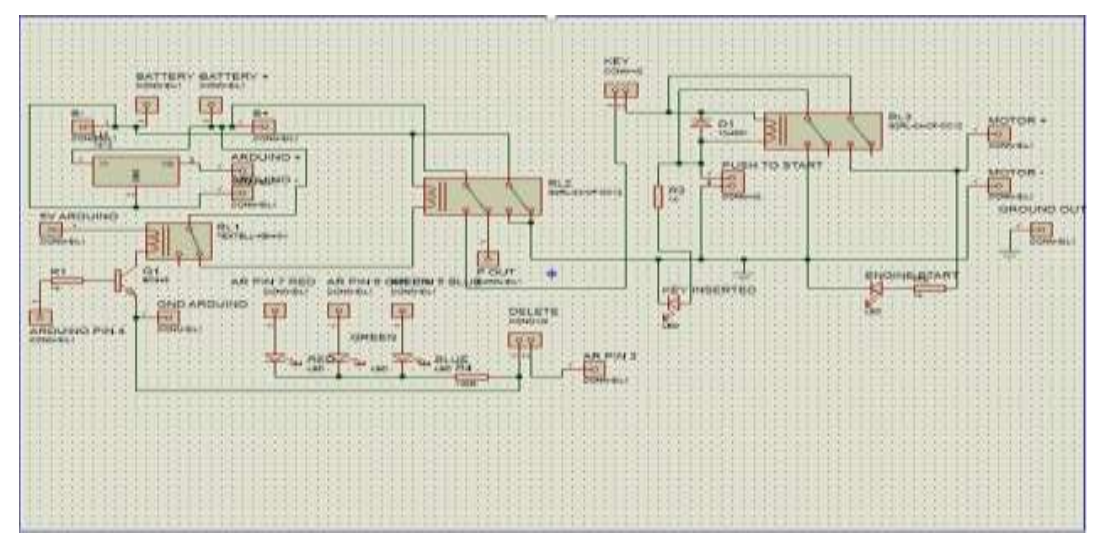

Fig. 6 Designed circuit diagram of anti-theft system

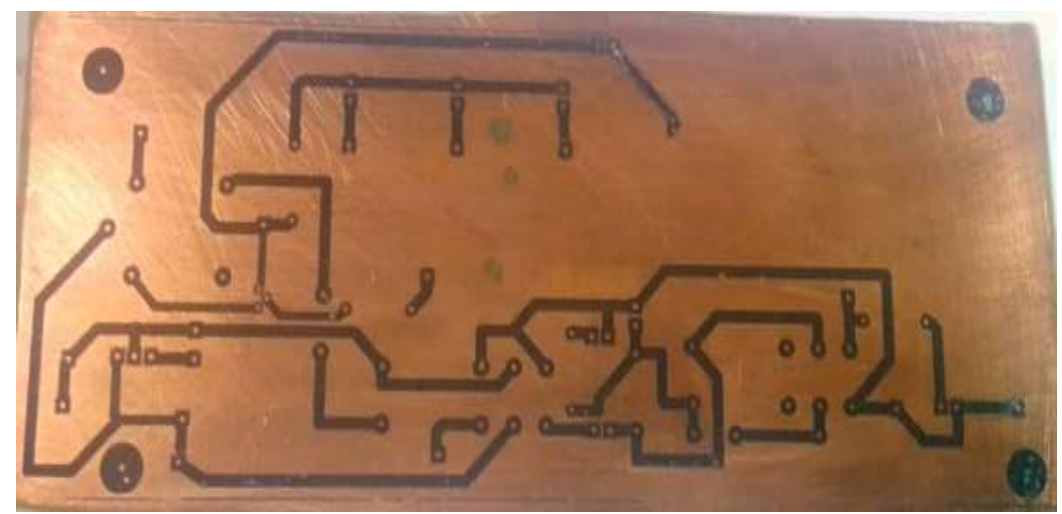

Fig. 7 Designed PCB layout 


\section{RESULT AND DISCUSSION}

The design and implementation procedure is carried out following three main steps. Initial design was done using Proteus software to ascertain the working of the Arduino. Secondly the entire system is built on a project boaard as shown in Fig.8 and Fig. 9. for temporary and initial physical testing and implementaion. Thirdly, the system was developed on a PCB for final testing and implementation. In stage two and three, a digital voltmeter was used to test the voltages at various points across the circuitry with a $12 \mathrm{~V}$ direct current (d.c.) source connectd across the input terminals. Finally, the whole system is cased in a $300 \mathrm{~mm}$ by $250 \mathrm{~mm}$ box as shown in Fig. 10.

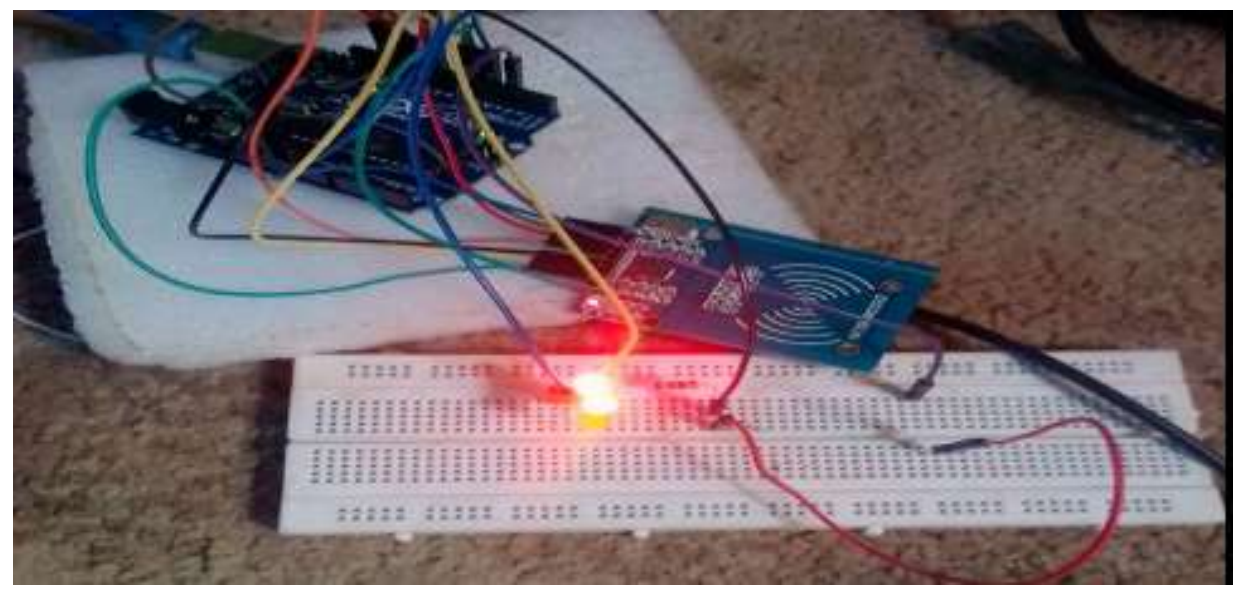

Fig. 8 Temporary built and implemented system on a project board

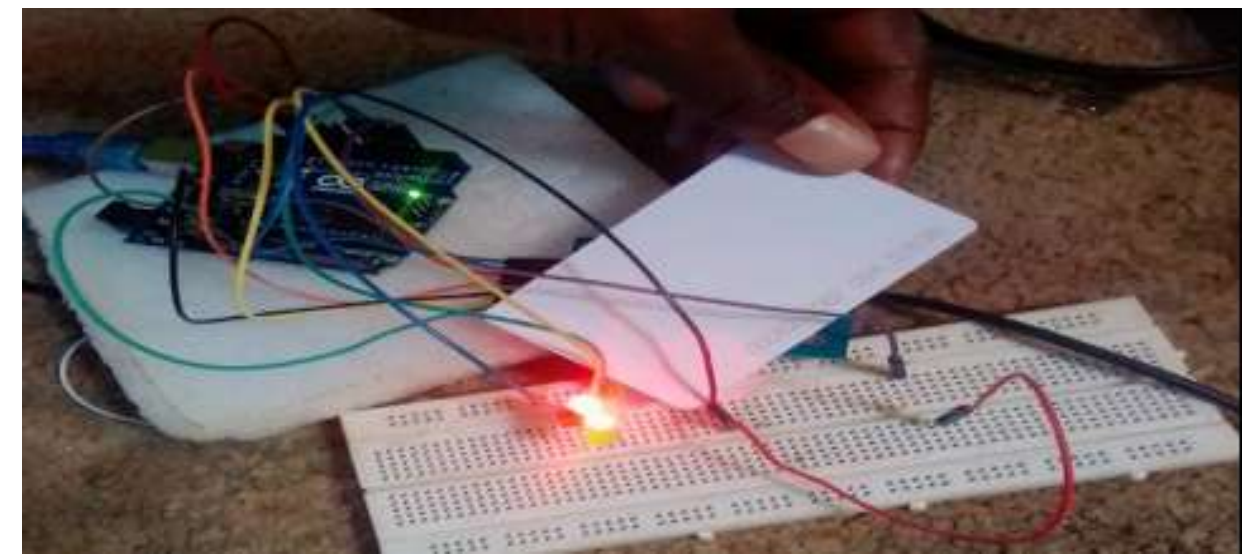

Fig. 9 Temporary built and implemented system on a project board with RFID card

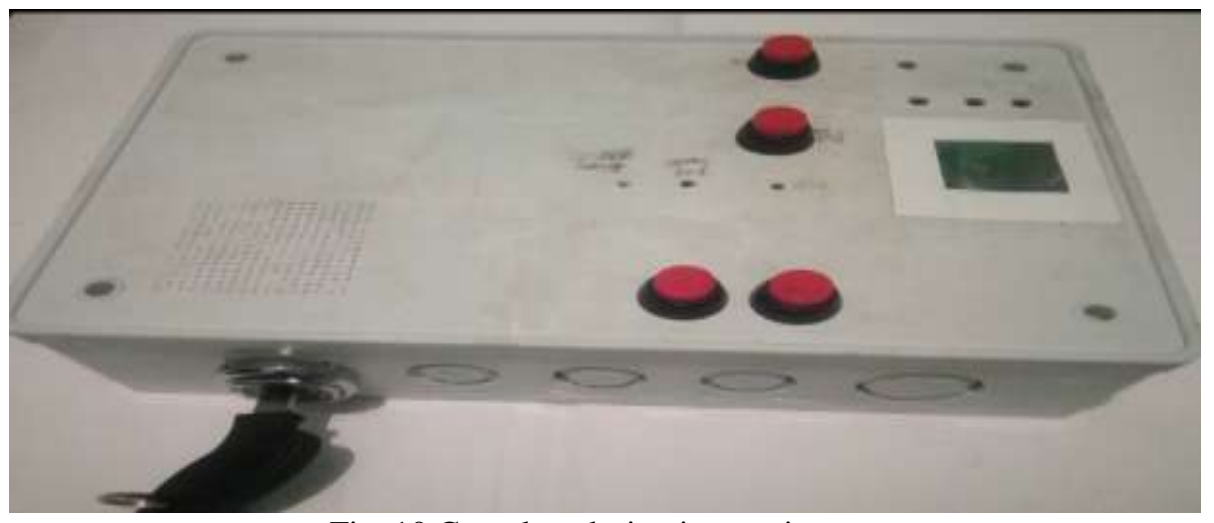

Fig. 10 Complete design in a casing

The circuit consists of three sections including alarm, immobilizer and Arduino sections. The alarm detects any unauthorized access to the car or the opening of any compartments of the car like the fuel tank and so on. When an authorized user opened the door of the car using authorized RFID card, it is expected of the user to close the 
door in less than 15 minutes. If this is not, the alarm is triggered. Also, the alarm is triggered instantaneously if any of the compartments of the car is opened by an unauthorized user. As an added security strategy, the immobilizer ensures that the car engine stops if other strategies fail. It prevents an unauthorized user thereby stopping the engine from further dynamic motion. Power is gained by the immobilizer anytime the alarm is shut off employing the RFID that is directly equipped to transfer power. Actually, the car cannot start until the right key is introduced or inserted, and the secret knob is pressed. In order to make the car start, inserting the key in the ignition must be followed by pressing the knop or button. The Arduino provides the keyless access into the car using the RFID card to gain entry to the car by an authorized user. This makes the alarm to turn off automatically and power is then transfer to the immobilizer. Without power transfer from the alarm to the immobilizer at the time the key is introduced into the ignition and the secret button pressed, the car will not start.

\section{Conclusions}

The paper has presented a car security system to prevent unauthorized or theft access. The concept of operation is built around radio frequency identification (RFID) security system which provides some sort of keyless function to access the car. The entire mechanism is based on the fact that the alarm is triggered to action at any time the car is accessed by an unauthorized person. With the alarm deactivated, power is transferred to the engine through the immobilizer in standby way. The engine starts when the key is inserted into the ignition with the secret button pushed. Nevertheless, with RFID accepted, the relay is triggered that turns on the immobilizer. If the engine is in any way turned OFF eventually and it is attempted to be ON again, the secret button must then be pressed by the user otherwise the car will not start. However, the system is yet to be successfully implemented in commercial or private vehicle, but the test results indicated promising outcome when eventually implemented.

\section{REFERENCES}

[1] R. R. Vinston, M. KrishnaRaj, R. SathisKumar, "Gen-X of Vehicle Anti-Theft System," International Journal Research in Science, Engineering and Technology, Vol. 4, Issue 3, pp. 829-835, 2015, DOI: 10.15680/IJIRSET.2015.0403004.

[2] P. Singh, T. Sethi, B. Bhusan S. K. Pattanayak, "A Smart Anti-theft System for Vehicle Security," International Journal of Materials, Mechanics and Manufacturing, Vol. 3, No. 4, 249-254, 2015, DOI: 10.7763/IJMMM.2015.V3.205

[3] K. Varsha, J. Choudhary, M. Kodgi, and M. S. Indira, "Barcode and RFID Based Security System," International Journal of Engineering Innovation and Research, Vol. 4, Issue 2, 272- 275.

[4] L. Rao, "Lookout: Lost and stolen smart phones will cost consumers over \$ 30b in 2012," 22 March 2012. [Webpage] Available:http://techcrunch.com/2012/03/22/lookout-lost-and-stolen- smartphones-will-cost consumers-over-30b-in-2012.

[5] M. Robert, “The history of RFID technology,” RFID Journal, 16 (01), URL: http://www.rfidjournal.com/articles/view?1338

[6] D. Weldemedhin, "RFID based Anti-theft System for Metropolia UAS Electronics Laboratories" Bachelor of Engineering Electronics Thesis, Helsinki Metropolia University of Applied Science, 2016.

[7] Finkenzeler and Waddington, 2003, 41-44.

[8] Y. M. Lee, F. Cheng, Y. T. Leung, "Exploring the impact of RFID on supply chain dynamics," In proceedings of the 36th conference on winter simulation, 1145-1152, 2004.

[9] R. E. Floyd, RFID in Animal-Tracking Applications. Potentials, IEEE, 34 (5), 2015. URL:http://ieeexplore.iee.org.ezproxy.metropolia.fi/stamp/stamp.jsp?tp=\&arnumber=7243403

[10] P. V. Reddy, A. Kumar, S. M. K. Rahman, and T. S. Mundra, “A new antispoofing approach for biometric devices”, IEEE Trans. Biomedical Circuits Systems, vol. 2, no. 4, pp. 328-337, Dec. 2008.

[11] C. Atuegwu, K. Okokpujie, and E. Noma-Osaghae, “A Bimodal Biometric Student Attendance system," 2017 IEEE 3rd International Conference on Electro-Technology for National Development (NIGERCON), 464-471, 2017.

[12] M. Borkar, "User identification systems leverage smarter biometrics technologies"” Texas Instrument, White Paper, 1-6, 2012.

[13] K. A. Rhodes, Information Security: Challenges in Using Biometrics, United States General Accounting Office, 2003.

[14] S. Prabhakar, S. Pankanti and A. K. Jain, Biometric recognition: Security and privacy concerns, IEEE Security and Privacy, vol.1, no.2, pp.33-42, 2003.

[15] S. M. S. Ahmad, B. M. Ali, and W. A. W. Adnan, "Technical Issues and Challenges of Biometric Applications as Access Control Tools of Information Security," International Journal of Innovative Computing, Information and Control, Vol. 8, No. 11, 7983-7999, 2012. 
[16] Administrator, "RFID Technology and Its Applications," Electronics Hub, 2015. https://www.electronicshub.org/rfid-technologyand-its-applications/ (Sourced: October 10, 2018)

[17] Jayendra, S. kumarawadu, and L. Meegahapola, "RFID-based anti-theft auto security system with an immobilizer," Conference Proceedings - 2nd International Conference on Industrial and Information Systems 2007 (pp. 441-446). USA: IEEE.

[18] R. Lomate, S. Mahore, B. S. Bhopale, N. R. Kharsan, "Smart Anti-Theft System for the Security of Vehicles- A Review," International Research Journal of Engineering and Technology (IRJET), Vol. 04, Issue 02, 1573-1576, 2017. 